\title{
Effects of Engineering and Geology Factors on Oil-Water Flow Regularity in Sandstone Reservoir with Bottom Water Drive
}

\author{
Mingkun Zhai, Gaoming Yu*, Yizhong Zhang, Chenchen Wang \\ Petroleum Engineering College of Yangtze University, Wuhan, China \\ Email: *ygm1210@vip.sina.com
}

How to cite this paper: Zhai, M.K., Yu, G.M., Zhang, Y.Z. and Wang, C.C. (2018) Effects of Engineering and Geology Factors on Oil-Water Flow Regularity in Sandstone Reservoir with Bottom Water Drive. Open Journal of Yangtze Gas and Oil, 3, 240-252. https://doi.org/10.4236/ojogas.2018.34021

Received: September 19, 2017

Accepted: October 23, 2018

Published: October 26, 2018

Copyright $\odot 2018$ by authors and Scientific Research Publishing Inc. This work is licensed under the Creative Commons Attribution International License (CC BY 4.0).

http://creativecommons.org/licenses/by/4.0/ (c) (i) Open Access

\begin{abstract}
The aim of this paper is to solve the problems such as complex morphology of water cone and ridge, as well as out-of-control flooding resulting from the abundant natural energy, formation heterogeneity and irregular inter-bed distribution. In this paper, the numerical simulation technique combined with the orthogonal experimental design method is applied to study the factors of engineering and geology that affect the oil-water flow regularity on Tahe sandstone reservoir with bottom water, such as reservoir permeability, liquid production rate, interlayered property and scale and location, liquid production rate, length of horizontal well etc. Results show that reservoir permeability, inter-layer and liquid production rate are key factors that influence the performance of coning and ridging water; the optimal lengths of horizontal wells change with different permeability formation. Besides, inter-layer physical properties also play an important role in the vertical well location. This study could provide theoretical and technical guidance for the early well spacing, the technical strategy of development as well as measures for water control and stability in sandstone reservoir with bottom water.
\end{abstract}

\section{Keywords}

Sandstone Reservoir with Bottom Water, Horizontal Well, Water Crest, Mechanism, Numerical Simulation

\section{Introduction}

The oil recovery and water cut are high in sandstone reservoir with bottom water drive with continuously supplying energy. However, Smith C.R.'s and others show that the formation of the bottom water cone is caused by the pressure gradient during oil production [1]. When the pressure gradient exceeds the critical 
value, the bottom water upwardly invades from the oil-water contact, after the well completion is filled with bottom water. The density of water is greater than that of oil, and the gravity effect relieves the bottom water cone in some extent, so that there is a dynamic balance between the gravity gradient and pressure gradient caused by the producing liquid. If the pressure gradient exceeds the gravitational gradient, the bottom water enters the perforation (breakthrough), the water cut increases rapidly, which leads to the water cone and ridge along the advantages of channel, and the part of oil that is not bypassed forms the irreducible oil.

Due to the unique sedimentation types, the porous medium and flow matrix of sandstone reservoirs with the bottom water, Yu, Aggour M. A., Khana I. S. and Jin Lu have gotten that its coning rule, mining mechanism and the development characteristics are fundamentally different from the conventional limestone reservoirs [2] [3] [4]. In order to study the problem of controlling the water cone, many reservoir engineering scholars have proposed their own relevant theory through analytical model, indoor physical simulation and numerical simulation technology. Wojtanowicz A.K. \& Shirman E. developed a method of controlling the bottom water cone by draining water, which is able to change the pressure around the perforation interval to adjust the oil production and drainage speed and then control the bottom water cone [5] [6]. Cheng et al. studied the production formula and the time against water prediction equation of the horizontal well ridge in the bottom water flooding reservoir [7]. Li et al. studied the critical yield formula of the oil well in bottom water reservoir with barrier plate [8]. Guo and Lee showed that the perforation should be away from the oil and water interface [9]; Smith and Pirson developed theory of backfilling oil back to the reservoir [1]; Abass and Bass studied the method of producing oil below the critical rate [10]; Karp et al. proposed the technology of injecting the polymer or gel to form sandwich in the oil and water coexistence area [11]. Chaperson presented the technology of using the horizontal wells to explore reservoirs [12]. Finally, the consideration of the economic factors and the shortage of engineering technology can't be fully realized. At present, there is sufficient research on the theoretical equations about the critical velocity, breakthrough time etc. [13] and engineering method such as the technology of controlling coning and water plugging. However, they are not suitable for 9-zone Bottom Water Sandstone Reservoirs specially.

Therefore, based on the existed experience, the oil and water flow law and development mechanism are studied by using the method of petroleum reservoir engineering and numerical simulation. In order to guide development practice in the bottom water reservoir of Tahe oilfield, the oil and water flow pattern is further explored. And the relevant study objectives are as follows.

- Build the Mechanism Model of Oil-water Flow in Bottom Water Sandstone Reservoir by Using Related Geological Parameters and Penetration Curve of Tahe Reservoir 
- Analyze the relationship between development index, such as the recovery and water cut, and geological and engineering factors, such as permeability, the length of horizontal well, liquid production rate and sandwich distribution.

- Evaluate the sensitivity of each factor to the development index by using the orthogonal design principle

\section{Geologic Model}

Numerical simulation is a method using the computer to solve the reservoir mathematical model, simulate the underground water flow, and give a time of oil and water distribution to predict the reservoir dynamics. The parameters of reservoir physical characteristics are originated from the Tahe oilfield, and the corresponding model has been built, which is close to the actual formation. The relevant parameters are as follows: the mid-depth is $3666 \mathrm{~m}$, the effective thickness is $12 \mathrm{~m}$, the depth of oil/water interface is $3672 \mathrm{~m}$, the porosity is 0.208 , the permeability is $733.3 \mathrm{mD}$, the initial oil saturation is 0.608 , the permeability is 1.33 , the oil density is $0.787 \mathrm{~g} / \mathrm{cm}^{3}$, the water density is $1.141 \mathrm{~g} / \mathrm{cm}^{3}$, the volume coefficient is 1.34 , the oil-water viscosity is 2.78 and $0.602 \mathrm{MPa}$ respectively. There is a production well in the center of dimensional coordinates of the geological model with the top surrounded by closed boundaries. A grid system is consisted of $56 \times 35 \times 25$ grids in the $X-Z-Y$ three directions, with the vertical layer located at 1 st - 24th layer (Table 1), and the water layer as the Fetkovich Aquifers located at the 25th layers, which is presented in Figure 1 and Figure 2.

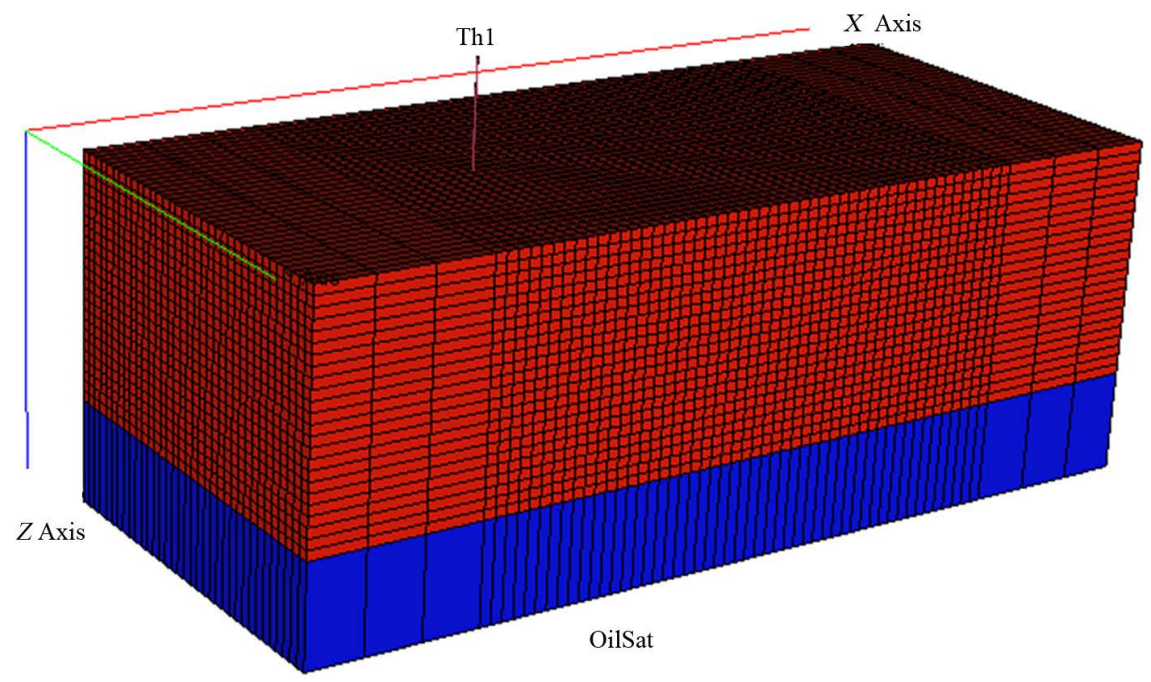

Figure 1. Reservoir 3D geological model.

Table 1. The sizes of Blockcentred grids.

\begin{tabular}{ccccccc}
\hline & \multicolumn{2}{c}{ DX } & & \multicolumn{2}{c}{$\mathrm{DZ}$} \\
\cline { 1 - 2 } \cline { 5 - 6 } 1st - 3rd layer & 4 th -53 th layer & 54 th -56 th layer & & & 1st -24 th layer & 25th layer \\
\hline 50 & 10 & 50 & 10 & 0.5 & 5 \\
\hline
\end{tabular}




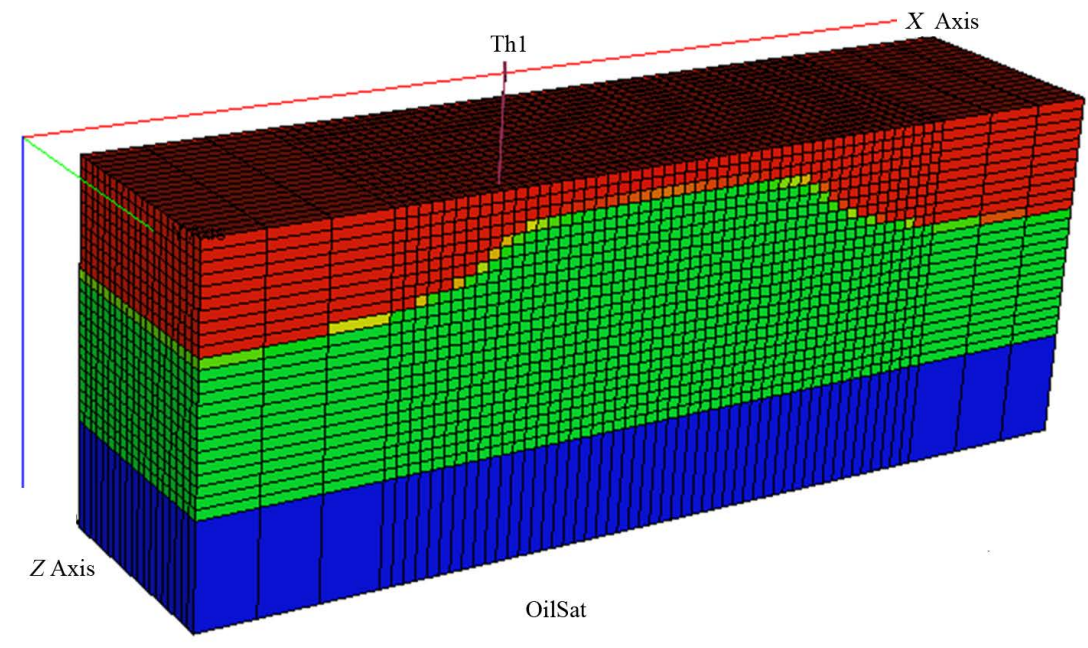

Figure 2. The pattern of water ridge.

\section{Simulation Results of Factors Influencing Bottom Water Coning}

\subsection{Reservoir Permeability}

There are six types of permeability which is consisted of 100, 300, 500, 700, 900 and $1200 \mathrm{mD}$ to simulate the influence of permeability on oil-water flow in the presence of $130 \mathrm{~m}^{3} / \mathrm{d}$.

As is shown in Figures 3-5, lower permeability is more sensitive to the recovery ratio and water cut, and the reservoir permeability is logarithmically related

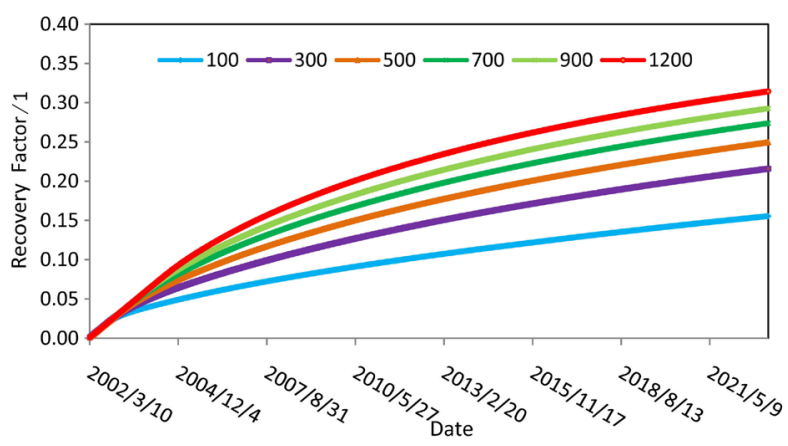

Figure 3. Relation between permeability and recovery factor.

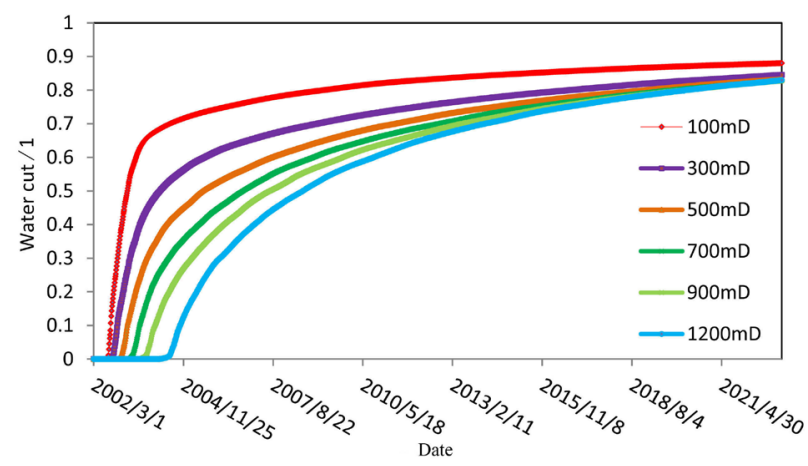

Figure 4. Relation between permeability and water cut. 


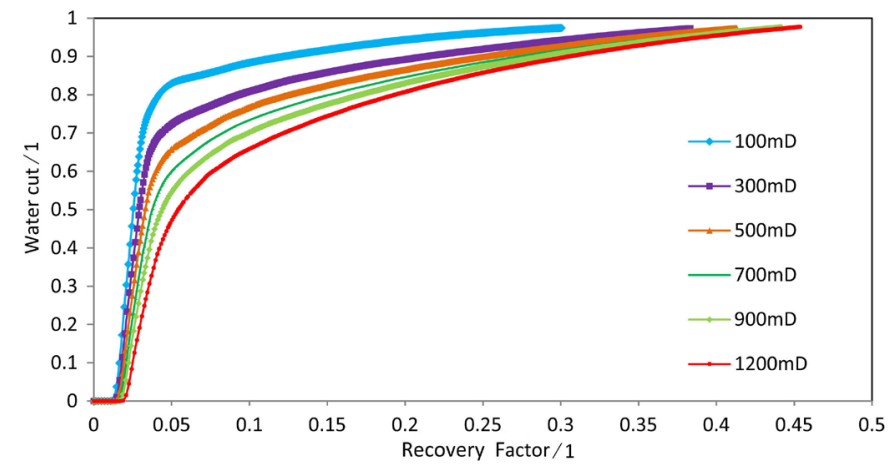

Figure 5. Water cut vs oil recovery factor under different permeability.

to the oil recovery ratio. The lower the reservoir permeability is, the more difficult the oil and water flow will be. When the permeability is less than $100 \mathrm{mD}$, the water cut and the recovery factor of the oil well keeps in a low level. With the increase of the permeability, the water breakthrough time is prolonged and the ultimate recovery factor is enhanced. The low recovery degree and the high water content correspond to the $100 \mathrm{mD}$ (permeability value). Along with the development of the reservoir, the bottom water flows into the bottom of the well, so that it could lead to water breakthrough along predominant pathway prematurely, which results in a dramatical increase of the water cut and a serious effect on the oil production. Facing the poor fluidity at the low permeability, the method of acid fracturing can be used to improve the water displacement effectively.

\subsection{Liquid Production Rate}

There are six types of liquid production rate that are consisted of 30, 50, 70, 100, $130,150 \mathrm{~m}^{3} / \mathrm{d}$ to simulate the influence of liquid production rate on oil-water flow at $700 \mathrm{mD}$ homogeneous reservoir to simulate the influence of daily fluid production rate.

As is shown in Figures 6-8, the trend line is made up of several points in Figure 6 and Figure 7. According to the researches, the increase of liquid production rate will reduce the ultimate recovery efficiency and prolong the breakthrough time. There is a logarithmic relationship between the velocity and the recovery degree. In addition, it is less sensitive than reservoir permeability to the recovery factor. The effect of medium and low level of the reservoir is relatively significant on the water cut and the water breakthrough time is shortened with the increase of the daily liquid production rate. It could be seen that the daily fluid production rate does not affect the final recovery rate (water rate of 98\%). Meanwhile all curves trend to be the same one when the water cut attains 0.85 , which means the increase of the daily liquid production rate could shorten the development period. In the two factors cross-plot (Figure 9), the final water cut is binomially relative with permeability under different liquid production rates. With the increase of the liquid withdraw rate, the water cut is more sensitive to permeability. Based on the research studied by Aliriza Bahadori, the production 
M. K. Zhai et al.

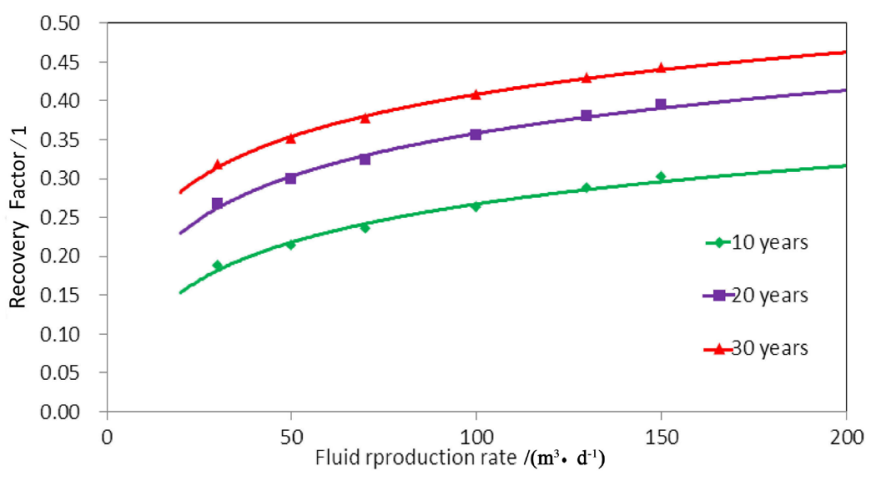

Figure 6. Relation between production rate and recovery factor.

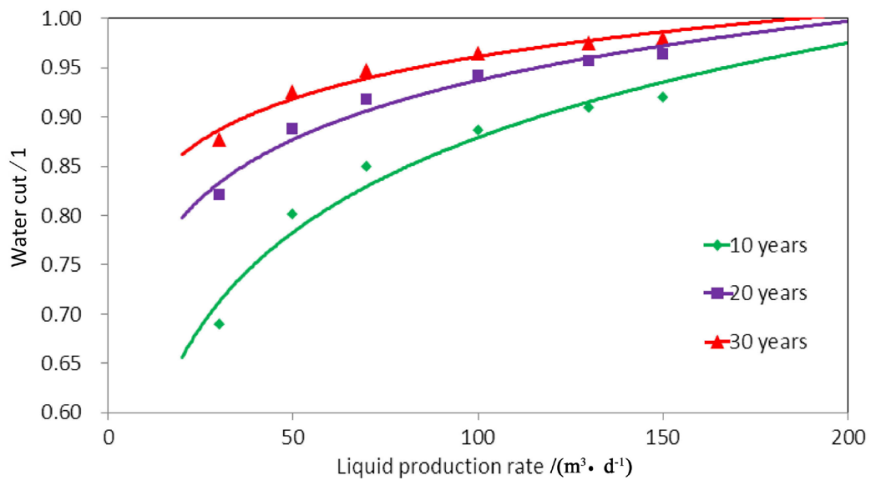

Figure 7. Relation between permeability and water cut.

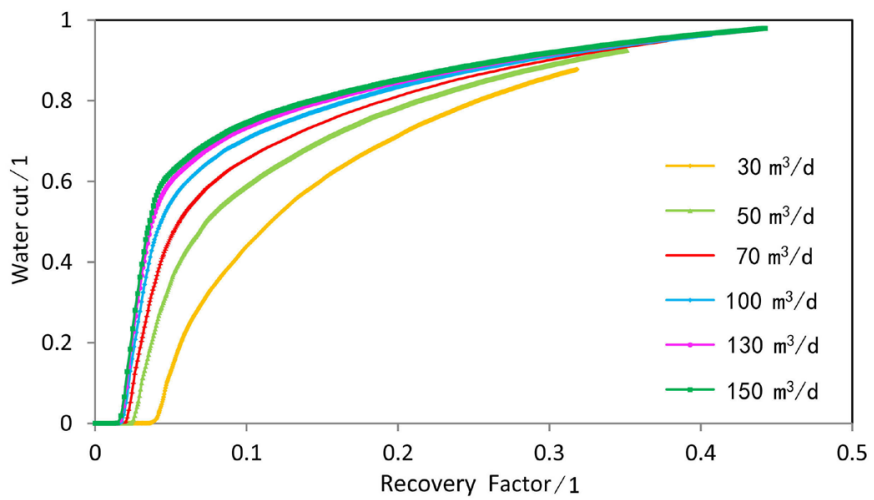

Figure 8. Water cut vs oil recovery factor in different production rate.

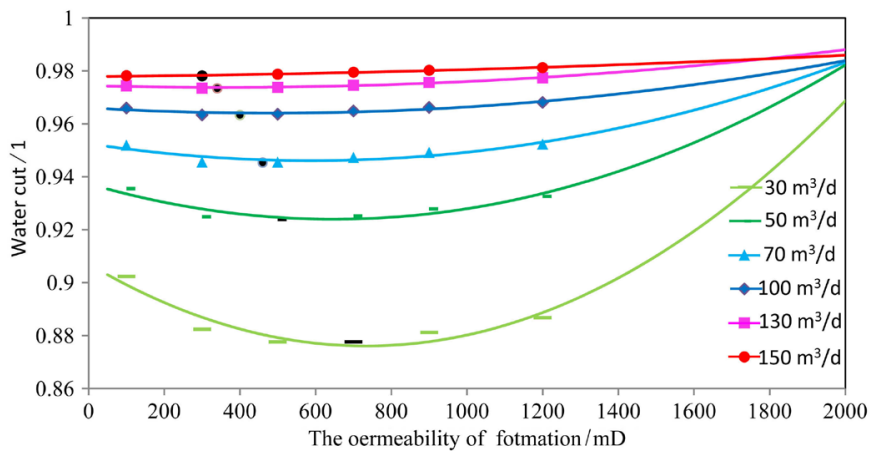

Figure 9. Relation between production rate and permeability and recovery ratio. 
pressure's increase resulted from the high daily liquid production rate, combined with smooth flow channel, which contributes to the quick coning of the bottom water and the reservoir were seriously flooded before the oil well product water [14]. And the development effect is worse. Reasonable daily fluid production rate can effectively reduce the water content with different reservoir physical properties.

\subsection{Length of Horizontal Well}

There are four velocities of the length of the well stage that consist of 200, 300, 400, $500 \mathrm{~m}$ horizontal section to simulate the influence of length of the well stage on oil-water flow in the $700 \mathrm{mD}$ homogeneous reservoir under $130 \mathrm{~m}^{3} / \mathrm{d}$ liquid production rate .

As is shown in Figure 10 and Figure 11, the trend line is made up of several points in Figure 9 and Figure 11. Chen et al. studied that the horizontal wells are widely applied in the development of bottom water reservoirs with the advantages of large drainage area and small producing pressure [15]. Other people, such as Yue ping, have deeply analyzed a series of problems of horizontal wells and impermeable and seim-permeable barrier [16] [17]. The increasing length of the horizontal interval can prolong the water-free oil production period and enhance the degree of reserve recovery. During the long production period, the water cut can be effectively reduced with the longer horizontal well. Liu, et al. and Tang, et al. tell us that the horizontal well is affected by friction, acceleration loss, hole roughness and mixed pressure drop in the wellbore [18] [19]. In view of the interaction between the reservoir permeability and horizontal length in Figure 11, the sensibility of horizontal length to water cut firstly increases and then decreases and finally increases with the increase of permeability. In addition, there exists a reasonable length at horizontal intervals of horizontal wells, which is an optimal value with $700 \mathrm{mD}$ actual average reservoir permeability. Under this condition, the friction pressure drop is the least, and the water cut is the lowest which is beneficial to the actual development, Patil, R. N.; Vinjamur, M.; Mitra, S. K. also studied relevant achievements [20].

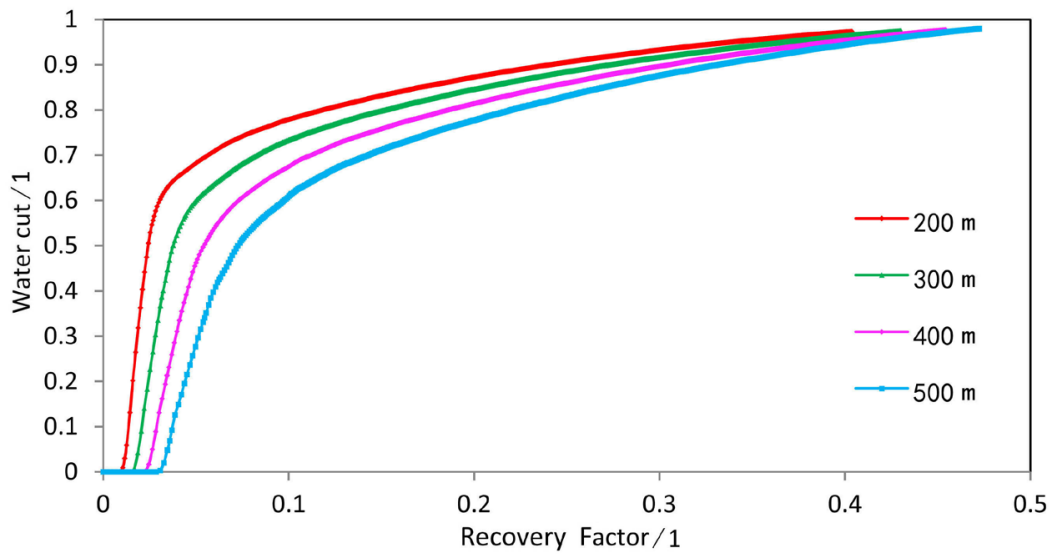

Figure 10. Water cut vs oil recovery factor under different horizontal length. 


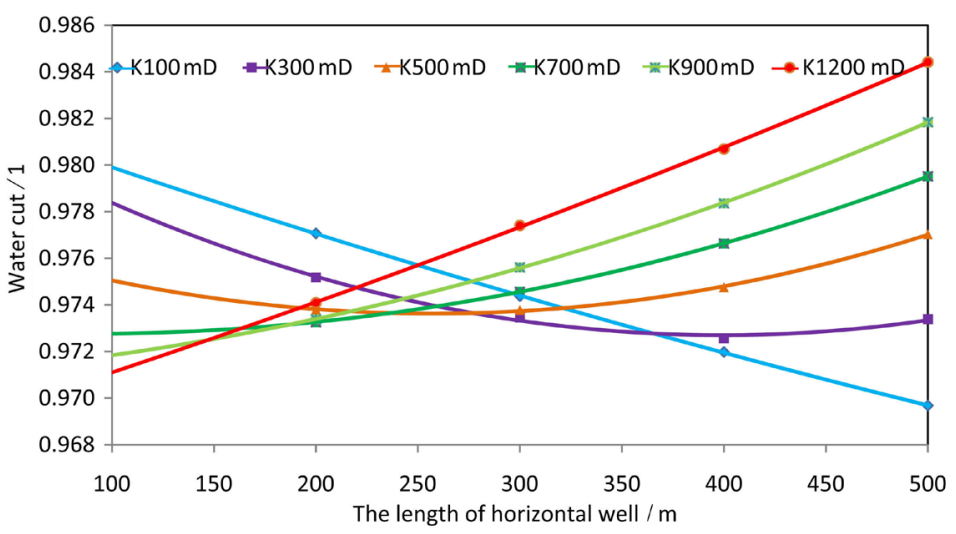

Figure 11. Relation between permeability and horizontal length and water cut.

\subsection{Property, Scale and Position of Sandwich}

There are three factors which consist of six sandwich properties $0,0.1,1,10$ and $15 \mathrm{mD}$, four sandwich scales $1 / 100,1 / 15,1 / 4,9 / 16$ of the model area, four locations at $1 / 4,1 / 2,2 / 3,1$ of the height to simulate the influence of interlayer on oil-water flow in a $700 \mathrm{mD}$ homogeneous reservoir under $130 \mathrm{~m}^{3} / \mathrm{d}$ production rate.

As is shown in Figures 12-14, the trend line is made up of several points in Figure 13 and Figure 14. The oil recovery increases early and then decreases

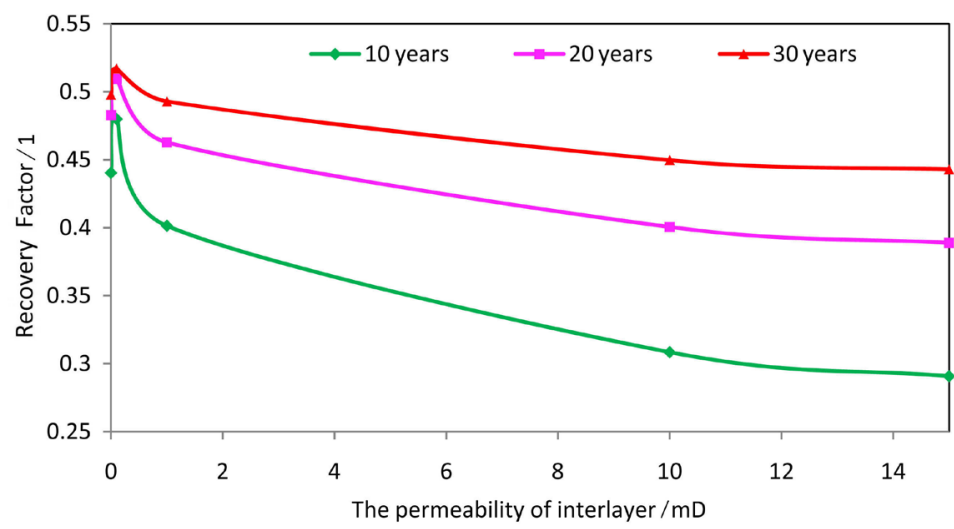

Figure 12. Relation between permeability of interlayer and recovery factor.

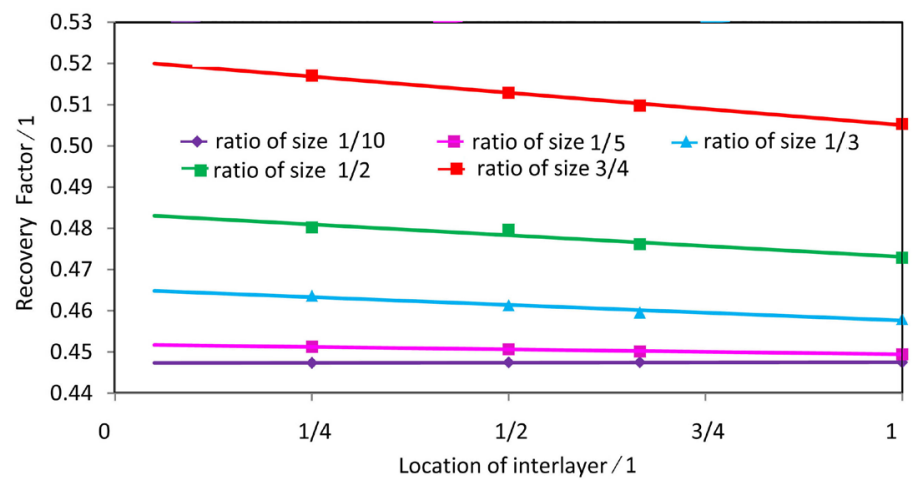

Figure 13. Relation between location/scale of interlayer and recovery ratio $(K=0.1 \mathrm{mD})$. 


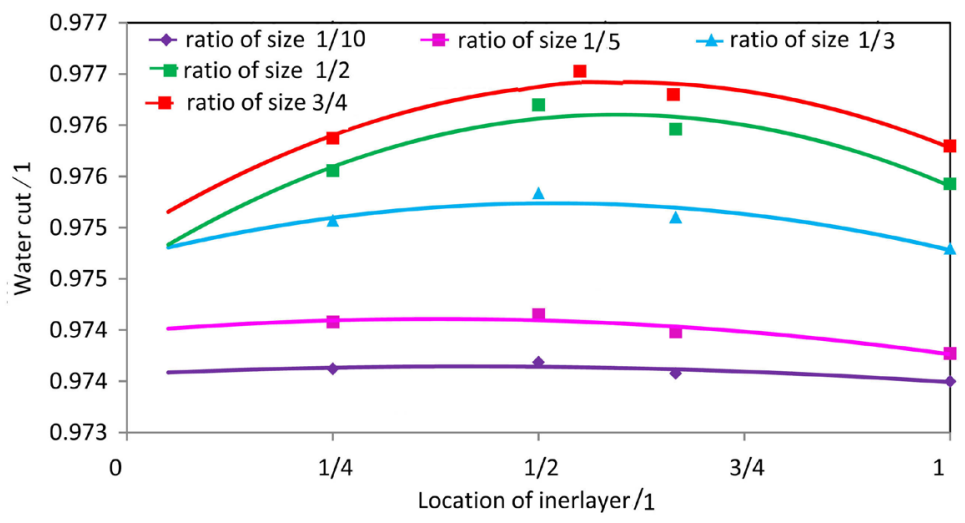

Figure 14. Relation between location/scale of interlayer and recovery ratio $(K=10 \mathrm{mD})$.

with the increase of interlayer permeability in different development years. When the interlayered permeability is higher than $15 \mathrm{mD}$, the recovery is almost unaffected by the interlayered permeability. Based on the fact that the bottom water plays double vertical and plane displacement role in oil-water flow when the interlayered permeability is $0.1 \mathrm{mD}$, the interlayer has an optimal permeability, which could contribute to the improvement of oil recovery factor and swept volume; In Figure 13 and Figure 14, when the permeability is less than $10 \mathrm{mD}$, the interlayer is closer to the perforation interval, which causes the higher recovery factor; when the interlayered permeability is no less than $10 \mathrm{mD}$, the sandwich location exists the optimal value, which means that the perforation should be kept at the same distance from the interlayer as the interlayer is far away from oil/water contact. The scale of the interlayer and the recovery rate is co-linear. During the same production life, the larger scale of sandwich is conducive to the actual development within the different reservoir physical properties. There is eaves oil in the bottom of small-scale low-permeability ultra-low permeability sandwich. Xue, et al., Li, et al. and Zheng et al. have got that the wells are depleted development, and a large amount of roof oil is located at the upper and lower adjacent layer which can be used as a late focus on the potential of the object [21] [22] [23] [24].

\section{Sensitivity Test}

According to the advantage that the orthogonal test could take the result of multi-factor interaction into account and avoid the impact of comprehensive experimental program and the cumbersome date, we could adapt the orthogonal test to reduce the number of tests and ensure the test results reliable. The interrelated influence of the eight factors such as the reservoir permeability, the length of horizontal wells, the property of an impervious break etc, are studied by applying this method in $\mathrm{L}_{27}$, and the sensitivity on the oil recovery is studied at the end of 30 years (Table 2).

The larger the range of the factor is, the more distinguished the influence on the recovery factor becomes. The order of the sensitivity is shown as follows: the reservoir permeability $>$ the property of sandwich $>$ the daily fluid production 
M. K. Zhai et al.

Table 2. Orthogonal design date for sensitivity factors study about bottom water cresting.

\begin{tabular}{|c|c|c|c|c|c|c|c|c|c|}
\hline $\begin{array}{l}\text { factor } \\
\text { Leve }\end{array}$ & $\begin{array}{c}K \\
/ \mathrm{mD}\end{array}$ & $Z$ & $\begin{array}{c}Q \\
/\left(\mathrm{m}^{3} \cdot \mathrm{d}\right)\end{array}$ & $\begin{array}{c}L \\
/ \mathrm{m}\end{array}$ & $\begin{array}{c}H \\
/ \mathrm{m}\end{array}$ & $\begin{array}{l}\text { Interlayer } \\
\text { property }\end{array}$ & $\begin{array}{c}\text { scale } \\
/(\mathrm{m} \times \mathrm{m})\end{array}$ & $\begin{array}{l}\text { location } \\
/ \mathrm{m}\end{array}$ & $\begin{array}{c}\text { FOE } \\
/ \%\end{array}$ \\
\hline 1 & 100 & 10 & 30 & 200 & 4 & lithologic & $200 \times 100$ & top & 18.6 \\
\hline 2 & 100 & 10 & 30 & 200 & 6 & physico & $300 \times 200$ & middle & 24.1 \\
\hline$\cdots$ & $\cdots$ & $\cdots$ & $\cdots$ & $\cdots$ & $\cdots$ & $\cdots$ & $\cdots$ & $\cdots$ & $\ldots$ \\
\hline 27 & 800 & 1 & 50 & 200 & 8 & physico & $200 \times 100$ & bottom & 35.8 \\
\hline$K_{1}$ & 0.245 & 0.326 & 0.291 & 0.30 & 0.307 & 0.336 & 0.301 & 0.321 & \\
\hline$K_{2}$ & 0.351 & 0.319 & 0.318 & 0.32 & 0.328 & 0.352 & 0.321 & 0.322 & \\
\hline$K_{3}$ & 0.367 & 0.317 & 0.353 & 0.34 & 0.327 & 0.274 & 0.34 & 0.32 & \\
\hline range & 0.122 & 0.009 & 0.062 & 0.041 & 0.021 & 0.078 & 0.039 & 0.002 & \\
\hline optimal & 800 & 10 & 80 & 300 & 6 & physico & $400 \times 300$ & middle & \\
\hline sorting & 1 & 7 & 3 & 4 & 6 & 2 & 5 & 8 & \\
\hline
\end{tabular}

rate $>$ the length of the horizontal well $>$ the scale of the sandwich $>$ the vertical permeability-to-horizontal permeability ratio $>$ the position of the sandwich (Table 3). The optimum level of the factor is the highest value of the mean value $\left(K_{1}-K_{3}\right)$ : the reservoir permeability is $800 \mathrm{mD}$, the interlayer is permeable, the liquid production rate is $80 \mathrm{~m}^{3}$, and the optimum level of the eight factors is the highest value of the horizontal average $\left(K_{1}-K_{3}\right)$, the optimal combination is that the length of the horizontal well is $300 \mathrm{~m}$, the sandwich scale is the drainage area of $1 / 2$, the height of water avoidance is $6 \mathrm{~m}$, the vertical permeability-to-horizontal permeability ratio is 10 , the sandwich is located in the middle of the reservoir, which is almost the same result as the single variable method determining the reasonable parameters (Table 3 ).

Table 3. Analysis of variance of orthogonal experiment design.

\begin{tabular}{|c|c|c|c|c|c|c|c|c|c|}
\hline factor & $K / \mathrm{mD}$ & $\frac{K_{\mathrm{h}}}{K_{\mathrm{v}}} / 1$ & $\mathrm{Q} /\left(\mathrm{m}^{3} \cdot \mathrm{d}\right)$ & $L / \mathrm{m}$ & $H / \mathrm{m}$ & $K_{\mathrm{Bnd}} / \mathrm{mD}$ & $S_{\text {Bnd }} / \mathrm{mD}$ & location & deviation \\
\hline $\begin{array}{l}\text { sum of square } \\
\text { of deviations }\end{array}$ & 794.907 & 3.62 & 173.787 & 76.247 & 24.02 & 307.407 & 70.847 & 0.187 & 1451.02 \\
\hline $\begin{array}{c}\text { degrees } \\
\text { of freedom }\end{array}$ & 2 & 2 & 2 & 2 & 2 & 2 & 2 & 2 & 16 \\
\hline F ratio & 2.383 & 0.02 & 0.958 & 0.42 & 0.132 & 1.695 & 0.391 & 0.001 & \\
\hline F critical-value & 3.63 & 3.63 & 3.63 & 3.63 & 3.63 & 3.63 & 3.63 & 3.63 & \\
\hline significant & Extremely & not & highly & little & little & Extremely & little & not & \\
\hline
\end{tabular}

In order to study the influence of factors on the development effect, we need further analysis variance. Based on the significance of the factors, the reservoir 
permeability and the sandwich property are more sensitive than others in the oil recovery. And the daily liquid production rate, the scale of sandwich, the length of horizontal well and the height of water avoidance are little sensitive to the oil recovery; the effect of the sandwich position is not significant. Therefore, based on the formation physical property and the distribution of sandwich, the reasonable wells pattern and a reasonable working system are adopted to control the bottom of the water crest and cone implementing scheme in the field effectively.

\section{Conclusions}

By analyzing the mechanism of the water cone and ridge, a simplified numerical model has been built combined with the engineering and geology parameters. 8 factors in the model are simulated which affect oil-water flow regularity in sandstone reservoir with bottom water drive, evaluating the significance to development index. From this study it is clear that:

- The mechanism model can present the phenomenon of water coning and cresting in bottom water reservoir in some extent.

- The permeability of the reservoir and intermediate layer is more sensitive to the oil-water flowing than other factors, such as the daily fluid production rate, the scale and location of sandwich and so on.

- The water content will be more sensitive to the reservoir permeability with the decrease of the daily liquid production rate.

- As the permeability of the reservoir increases, the sensitivity curve of water-cut to the length of horizontal well climbs up and then declines and then increases, which means the optimum horizontal length.

- The various combination patterns of sandwich property and locations could contribute significantly different impacts on the oil water flow. The perforated section will immediately be adjacent to the bottom of the low-permeability or ultra-low permeability sandwich, and it should be kept at the same distance from the conventional impermeable interlayer as the interlayer is far away from oil/water contact to inhibit the water cone and crest.

\section{Acknowledgements}

This study was supported by national science and technology major projects of China (2016ZX05031004-001-002). Thanks to my supervisor Professor Yu Gaoming for his careful guidance.

\section{Conflicts of Interest}

The authors declare no conflicts of interest regarding the publication of this paper.

\section{References}

[1] Smith, C.R. (1963) Water Coning Control in Oil Wells by Fluid Injection. Society of 
Petroleum Engineers Journal, 4, 314-326. https://doi.org/10.2118/613-PA

[2] Yu, G.M., Ling, J.J. and Jang, M.X. (1996) Production Mechanism and Development Tactics on Sandstone Reservoirs with Bottom Water. Journal of Jianghan Petroleum Institute, 3, 59-62.

[3] Aggour, M.A. and Khana, I.S. (2007) HELE-SHAW Model Study of Horizontal Well Performance in Reservoir with Gas Cap and Bottom Water Drive. Petroleum Science and Technology, 19, 661-672.

[4] Jin, L. and Wojtanowicz, A.K. (2013) An Analytical Model for Water Coning Control Installation in Reservoir with Bottom Water. Canadian International Petroleum Conference, Calgary, 16-18 June 2013, SPE-PA 137787.

[5] Wojtanowicz, A.K., Xu, H. and Bassiowni, Z.A. (1991) Oil Well Coning Control Using Dual Completion with Tailpipe Water Sink. SPE Production Operation Symposium Held in Oklahoma City, 7-9 April 1991.

[6] Shirman, E.I. and Wojtanowicz, A.K. (1998) More Oil with Less Water Using Downhole Water Sink Technology: A Feasibility Study. SPE Annual Technical Conference \& Exhibition, New Orleans, 27-30 October 1998. SPE Paper 49052.

[7] Cheng, L.S. and Lang, Z.X. (1994) Reservoir Engineering Problem of Horizontal Wells Coning in Bottom-Water Driven Reservoir. Journal of the University of Petroleum, 18, 44-47.

[8] Li, C.L. and Song, H.C. (1993) Computation Formula of Critical Production Oil Water Reservoir with Bottom Water and Confining Bed. Petroleum Geology \& Oilfield Development and Daqing, 12, 43-45.

[9] Guo, B. and Lee, R.L.H. (1993) A Simple Approach to Optimization of Completion Interval in Oil/Water Coning Systems. SPE Reservoir Engineering Journal, 249-255, SPE23994.

[10] Abass, H.H. and Bass, D.M. (1988) The Critical Production Rate in Water Coning System. Permian Bas in Oil and Gas Recobery Conference, Midland, 10-11 March 1988, SPE17311. https://doi.org/10.2118/17311-MS

[11] Karp, J.C., Lowe, D.K. and Marusov, N. (1962) Horizontal Barriers for Controlling Water Coning. Journal of Petroleum Technology, 783-790.

https://doi.org/10.2118/153-PA

[12] Chaperson, I. (1986) Theoretical Study of Coning toward Horizontal and Vertical Wells in Anisotropic Formation: Subscritical and Critiacal Rate. Annual Technical Conference and Exhibition, New Orleans, 5-8 October 1986, SPE 15377.61. https://doi.org/10.2118/15377-MS

[13] Amarfio, E.M. (2013) Breakthrough Time Correlations for Coning in Bottom Water Supported Reservoirs. SPE Nigeria Annual International Conference and Exhibition, Lagos, 5-7 August 2013, SPE 167511.

[14] Bahadori, A. (2010) Determination of Well Placement and Breakthrough Time in Horizontal Wells for Homogeneous and Anisotropic Reservoirs. Journal of Petroleum Science and Engineering, 75, 196-202. https://doi.org/10.1016/j.petrol.2010.11.007

[15] Chen, Z.H. (2000) Developing Bottom Water Pools with Horizontal Well. Oil \& Gas Geology, 21, 214-219.

[16] Yue, P., Du, Z.M. and Chen, X.F. (2012) The Critical Rate of Horizontal Wells in Bottom-Water Reservoirs with an Impermeable Barrier. Petroleum Science, 9, 223-229.

[17] Yue, P., Du, Z.M. and Chen, X.F. (2015) Critical Parameters of Horizontal Well Influenced by Semi-Permeable Barrier in Bottom Water Reservoir. Journal of Central 
South University, 22, 1448-1455.

[18] Liu, X.P. (2003) The Model Coupling Fluid Flow in the Reservoir With Flow in the Horizontal Wellbore. Acta Pertrolei Sinica, 24, 82-86.

[19] Tang, L. and Gao, J. (2013) Research on Inhibition of Water Coning of Water Recovery in Edge-Bottom Water Reservoir with Interlayer. Reservoir Evaluation and Development, 3, 28-31.

[20] Patil, R.N., Vinjamur, M. and Mitra, S.K. (2013) The Optimization of the Length of Horizontal Wells for Bottom Water Reservoir Condition. Energy Sources Part A-Recovery Utilization and Enviromental Effects, 35, 2337-2347. https://doi.org/10.1080/15567036.2010.533338

[21] Li, G. and Zheng, H.N. (2013) Controlling of Bottom Water Coning in Horizontal Wells in Sandstone Reservoirs with Bottom Water-By Taking the Triassic Horizontal Wells in Sandstone Reservoirs with Bottom of TaHe Oilfield for Example. Journal of Oil and Gas Technolugy, 3, 67-74.

[22] Xue, Y.C. and Cheng, L.S. (2010) The Study on Inter-Bedded Stratum Model Control in Bottom Water Reservoir Development and Remaining Oil Distribution. Journal of Southwest Petroleum University, 32, 101-106.

[23] Zheng, H.N., Li, X. and Li, G. (2013) The Influencing Factors Analysis on Interlayer Controlling Bottom Water Coning in Sandstone Reservoirs. Xinjiang Geology, 31, 42-49.

[24] Xue, Y.C. (2010) Controlling Effect of the Interlayer on Remaining in the Bottom Water Sand Reservoirs. Journal of Daqing Petroleum Institute, 34, 67-72.

\section{Nomenclature}

FOR is the oil recovery of field \%;

$K$ is the permeability of the reservoir $\mathrm{mD}$;

$K_{\mathrm{h}} / K_{\mathrm{b}}$ is the ratio of vertical permeability to horizontal permeability;

$Q$ is the daily fluid of production rate $\mathrm{m}^{3} / \mathrm{d}$;

$L$ is the length of horizontal well $\mathrm{m}$;

$H$ is the height of water avoidance m;

$K_{\text {bnd }}$ is the permeability of interlayer $\mathrm{mD}$;

$S_{\text {bnd }}$ is the scale of interlayer $\mathrm{m}^{2}$. 